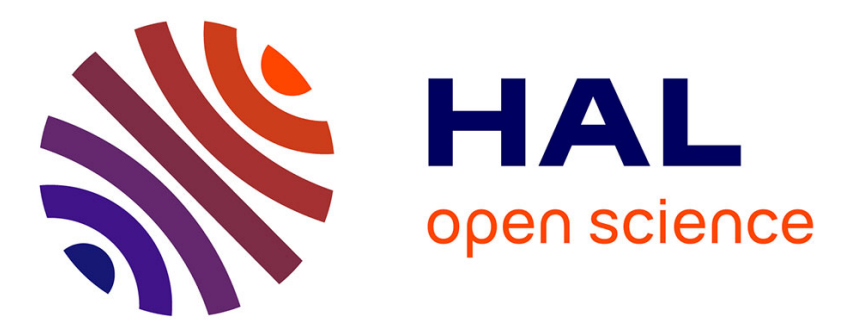

\title{
Identification of a novel 12-nucleotide insertion polymorphism in the promoter region of ADRA2B: full linkage with the 9-nucleotide deletion in the coding region and influence on transcriptional activity
}

Pierre-Antoine Crassous, Régis Blaise, Amélie Marquette, Amir Snapir, Mika Scheinin, Hervé Paris, Stéphane Schaak

\section{To cite this version:}

Pierre-Antoine Crassous, Régis Blaise, Amélie Marquette, Amir Snapir, Mika Scheinin, et al.. Identification of a novel 12-nucleotide insertion polymorphism in the promoter region of ADRA2B: full linkage with the 9-nucleotide deletion in the coding region and influence on transcriptional activity. Biochemical Pharmacology, 2009, 79 (3), pp.407. 10.1016/j.bcp.2009.08.024 . hal-00538092

\author{
HAL Id: hal-00538092 \\ https://hal.science/hal-00538092
}

Submitted on 21 Nov 2010

HAL is a multi-disciplinary open access archive for the deposit and dissemination of scientific research documents, whether they are published or not. The documents may come from teaching and research institutions in France or abroad, or from public or private research centers.
L'archive ouverte pluridisciplinaire HAL, est destinée au dépôt et à la diffusion de documents scientifiques de niveau recherche, publiés ou non, émanant des établissements d'enseignement et de recherche français ou étrangers, des laboratoires publics ou privés. 


\section{Accepted Manuscript}

Title: Identification of a novel 12-nucleotide insertion polymorphism in the promoter region of ADRA2B: full linkage with the 9-nucleotide deletion in the coding region and influence on transcriptional activity

Authors: Pierre-Antoine Crassous, Régis Blaise, Amélie

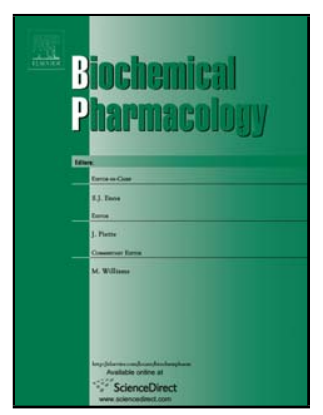

Marquette, Amir Snapir, Mika Scheinin, Hervé Paris,

Stéphane Schaak

PII:

S0006-2952(09)00727-8

DOI: doi:10.1016/j.bcp.2009.08.024

Reference:

BCP 10308

To appear in: $\quad B C P$

Received date: $\quad 9-6-2009$

Revised date: 26-8-2009

Accepted date: $\quad$ 26-8-2009

Please cite this article as: Crassous P-A, Blaise R, Marquette A, Snapir A, Scheinin M, Paris H, Schaak S, Identification of a novel 12-nucleotide insertion polymorphism in the promoter region of ADRA2B: full linkage with the 9-nucleotide deletion in the coding region and influence on transcriptional activity, Biochemical Pharmacology (2008), doi:10.1016/j.bcp.2009.08.024

This is a PDF file of an unedited manuscript that has been accepted for publication. As a service to our customers we are providing this early version of the manuscript. The manuscript will undergo copyediting, typesetting, and review of the resulting proof before it is published in its final form. Please note that during the production process errors may be discovered which could affect the content, and all legal disclaimers that apply to the journal pertain. 
Identification of a novel 12-nucleotide insertion polymorphism in the promoter region of ADRA2B : full linkage with the 9-nucleotide deletion in the coding region and influence on transcriptional activity

Pierre-Antoine Crassous ${ }^{\mathrm{a}, \mathrm{d}, 1}$, Régis Blaise ${ }^{\mathrm{b}}$, Amélie Marquette ${ }^{\mathrm{a}}$, Amir Snapir ${ }^{\mathrm{c}}$, Mika Scheinin ${ }^{\mathrm{c}}$, Hervé Paris ${ }^{\mathrm{a}, \mathrm{d}^{*}}$ and Stéphane Schaak ${ }^{\mathrm{a}, \mathrm{d}}$

a INSERM, U858/I2MR, team \#8, 1 avenue Jean Poulhès, BP 84225, 31432 Toulouse Cedex 4, France.

${ }^{\mathrm{b}}$ UMR7079, Physiologie et Physiopathologie, Université Pierre et Marie Curie, 7 Quai StBernard, BP 256, 75252 Paris Cedex 05, France.

${ }^{c}$ Department of Pharmacology, Drug Development and Therapeutics, University of Turku, FI20520 Turku, Finland.

${ }^{\mathrm{d}}$ Université Paul Sabatier, 31400 Toulouse, France

* Corresponding author:

Hervé Paris

INSERM, U858/I2MR, BP 84225, 31432 Toulouse Cedex 4, France.

Tel: 335613229 21, Fax: 33562172554

Email: herve.paris@inserm.fr

${ }^{1}$ Present address : Department of Anesthesiology, Johns Hopkins University, 720 Rutland Ave, Baltimore MD 21205, USA

Classification : Cardiovascular Pharmacology 


\begin{abstract}
The $\alpha_{2 \mathrm{~B}}$-adrenoceptor $\left(\alpha_{2 \mathrm{~B}}-\mathrm{AR}\right)$ mediates vasoconstriction and a common polymorphism (+901 Ins/Del), located in the coding region of the human $\alpha_{2 B}-A R$ gene (ADRA2B), has been demonstrated to affect receptor function in vitro. In this study, we have identified a novel polymorphism corresponding to the insertion of 12 nucleotides (GGGACGGCCCTG) at position -4825 relative to the start codon $(-4825$ del/ins $)$ in the far upstream region of the ADRA2B promoter. The genotyping of 71 unrelated Finnish individuals showed that the -4825 ins polymorphism is common and in complete linkage with the Del polymorphism at position +901 and a G/C substitution at position -98. Transfection of various cell lines with luciferase constructs containing a $5.5 \mathrm{~kb}$ fragment of the ADRA2B promoter region indicated that the 4825 ins polymorphism resulted in a large reduction of transcriptional activity. Electrophoretic mobility shift assays with oligonucleotide probes corresponding to the two ADRA2B alleles demonstrated that the region where the -4825 del/ins variation occurs binds nuclear proteins and that the 12 nucleotide insertion affects the pattern of bound transcription factors. Altogether, the present findings show that the previously identified +901 Del polymorphism is linked with a variation in the ADRA2B promoter that affects transcriptional activity in vitro. The molecular mechanisms underlying this effect are still unclear but a possible impact of the -4825 ins polymorphism on $\alpha_{2 \mathrm{~B}}-\mathrm{AR}$ expression would merit to be examined in vivo as a diminution of promoter activity may limit the functional consequences of the +901 Del polymorphism.
\end{abstract}

Keywords: adrenoceptor; ADRA2B promoter; polymorphism; transcription; haplotype. 


\section{Introduction}

The $\alpha_{2}$-adrenoceptors $\left(\alpha_{2}\right.$-ARs) are Gi/Go protein coupled receptors that are involved in the regulation of many physiological functions including central control of sympathetic tone, feedback auto-inhibition of neurotransmitter release from noradrenergic nerve endings, platelet aggregation and vasoconstriction. Based on divergent pharmacological properties and molecular cloning, $\alpha_{2}$-ARs consist in three subtypes $\left(\alpha_{2 \mathrm{~A}^{-}}, \alpha_{2 \mathrm{~B}^{-}}\right.$and $\left.\alpha_{2 \mathrm{C}^{-}} \mathrm{AR}\right)$ encoded by distinct intronless genes. Employment of mutation screening methods in the study of cohorts of individuals from various ethnic backgrounds has shown that all three human $\alpha 2$-AR genes are polymorphic and have variations in their third intracellular loops that modify either their biochemical properties or their coupling efficacy to cognate G-proteins [1]. Notably, a common polymorphism in the gene encoding the $\alpha_{2 B}-A R$ subtype (ADRA2B) has been identified [2]. This polymorphism, which corresponds to a 9-nucleotide deletion in the coding block (+901 Del), results in the removal of three glutamic acid residues in an acidic motif located in the third cytoplasmic loop of the receptor. Examination of the functional characteristics of the $\alpha_{2 \mathrm{~B}}-\mathrm{AR}$ variant in heterologous cell systems showed that the deletion does not affect ligand binding or G-protein coupling, but results in decreased GRK-mediated phosphorylation and attenuated receptor desensitization [3]. Hence the Del $\alpha_{2 B}-A R$ variant is expected to exhibit enhanced function. Clinical trials and epidemiologic studies investigating the consequences of the +901 Del variation on vascular responses to $\alpha_{2}$-agonist administration [4] or its possible association with cardiovascular diseases [5] have, however, yielded inconsistent results. Examination of a $5.8 \mathrm{~kb}$ genomic fragment comprising $2.2 \mathrm{~kb}$ upstream and $2.3 \mathrm{~kb}$ downstream from the coding sequence demonstrated the existence of several single nucleotide polymorphisms (SNPs) in different regions of the ADRA2B gene [6-8]. Most of these SNPs are rare, but nucleotide variations at positions -98, +1182 and +1776 are common and in linkage disequilibrium with the +901 Ins/Del 
polymorphism. Furthermore, the examination of variation frequency in different ethnic populations indicated that nine of the most common polymorphisms are organized in four major haplotypes, together representing $95 \%$ of both African American and Caucasian populations [8]. The significance of the different haplotypes for receptor expression is so far unknown. In the present work, we characterized a novel polymorphism located $4.8 \mathrm{~kb}$ upstream from the ADRA2B coding region (-4825 del/ins). This 12 nucleotide insertion polymorphism is common and, in the population studied in this work, in complete linkage with the previously described +901 Del polymorphism. The functional consequences of this variation were investigated by using reporter gene and electrophoretic mobility shift assays. 


\section{Materials and methods}

\subsection{Materials}

The BAC clone \# RP11-139J6 was obtained from the BACPAC Resource Center (Oakland, CA, USA). The expression vector containing the MZF-1 transcription factor (CB6-MZF-1) and the corresponding empty control vector (CB6) were generously donated by Dr R. Hromas (Indiana University Cancer Center, Indianapolis, IN, USA). The pNF-kB-Luc reporter vector was from Stratagene (La Jolla, CA, USA). Culture medium and fetal calf serum were purchased from Invitrogen (Life Technologies, Rockville, MD, USA). Restriction and DNA-modifying enzymes were from New England Biolabs (Ozyme, Saint-Quentin-en-Yvelines, France) and plasmids were purified using the Qiafilter Maxiprep kit (Qiagen, Courtaboeuf, France). Oligonucleotides were from Eurogentec (Seraing, Belgium), human recombinant $\mathrm{TNF} \alpha$ and all other compounds were from Sigma-Aldrich (St. Louis, MO, USA).

\subsection{Genotyping}

Genotyping was performed on samples collected from 71 unrelated, young and healthy Finnish men. The collection of DNA and the genotyping was approved by the Ethics Committee of the Southwestern Health Care District, Finland. All subjects gave their written informed consent. The genotyping method used to identify the +901 Del polymorphism has been described elsewhere [9]. The -4825 ins polymorphismwas determined on genomic DNA isolated from whole blood, using the sense primer ${ }_{5}$,ACGTGTAGAGGAAGAGGAAGG ${ }_{3}$, and the antisense primer ${ }_{5}$,AATGTCTGGAA-TACAGGGAGG 3 '. This set generates amplicons of $192 \mathrm{bp}$ for the 
deletion and of $204 \mathrm{bp}$ for the insertion allele. Moreover, digestion with Hae III yields fragments of 168 and $24 \mathrm{bp}$ for the deletion allele and of 118, $62 \mathrm{bp}$ and $24 \mathrm{bp}$ for the insertion allele. The PCR products or the fragments resulting from Hae III digestion were separated in $2.5 \%$ agarose gel and stained with ethidium bromide, and alleles were identified based on their different electrophoretic mobility.

\subsection{DNA sequencing}

Sequencing was performed by the dideoxy chain termination method using the BigDye ${ }^{\circledR}$ Terminator v3.1 cycle sequencing kit (Applied Biosystems, Foster City, CA, USA) and an automated DNA sequencer (ABI 3100, Perkin Elmer Applied Biosystems). DNA samples were sequenced on both strands, using the same primers as those used for genotyping.

\subsection{Luciferase constructs}

The luciferase constructs used in this study were generated as follows: the EcoRI-NotI restriction fragment (corresponding to nucleotides $-5505 /-603$ relative to the start codon) of the ADRA2B gene isolated from a human fetal genomic DNA library (Stratagene, Catalog $n^{\circ}$ 961200) [6] was first subcloned into the pBluescript ${ }^{\circledR} \mathrm{II} K S+$ vector (pKS, Stratagene). The resulting construct, pKS/ADRA2B-5505/-603[del], served as a template to insert the sequence GGGACGGCCCTG at position -4825 using the QuikChange ${ }^{\circledR} \mathrm{II}$ XL mutagenesis kit (Stratagene) and 5,ACCTGGTAATTCTTTATTGTGGGGACGGCCCTGAACCTTGCAGGACATTTGG ${ }_{3}$, and 5, CCAAATGTCCTGCAAGGTTCAGGGCCGTCCCCACAATAAAGAATTACCAGGT ${ }_{3}$, as sense and antisense primers. This procedure led to the pKS/ADRA2B-5505/-603[ins] construct. 
The construction of pGL3-derived vectors (Promega, Madison, WI, USA) containing the 1874/+3 region of the ADRA2B gene with a $G$ (pGL3/ADRA2B-1874/+3[G]) or a C (pGL3/ADRA2B-1874/+3[C]) at position -98 was previously described [6]. The generation of a pGL3-Basic vector, where an EcoRI site was created in the MCS by conversion of the SmaI sequence CCCGGG to CCCATCGAATTC, was also described earlier [10]. The EcoRI-SacII fragment of pKS/ADRA2B-5505/-603[del] (nucleotides -5505/-1034) was ligated to the SacIISalI fragment of pGL3/ADRA2B-1834/+3[G] (containing the $-1034 /+3$ region of ADRA2B and the luciferase gene) and the SalI-EcoRI of the pGL3-Basic (corresponding to vector backbone), to generate the pGL3/ADRA2B-5505/+3[del/G] construct. In a similar way, the ligation of the EcoRI-SacII fragment of pKS/ADRA2B-5505/-603[ins] with the SacII-SalI fragment of pGL3/ADRA2B-1834/+3[C] and the SalI-EcoRI fragment of pGL3-Basic led to pGL3/ADRA2B-5505/+3[ins/C], which harbors the 12-nucleotide insertion at position -4825 and possesses a $\mathrm{C}$ at position -98 . The construction of pGL3/ADRA2B-3160/+3[G], pGL3/ADRA2B-1034/+3[G] and pGL3/ADRA2B-1034/+3[C] construct has already been described [6]; pCMV- $\beta$ Gal was created by replacing the luciferase gene by a CMV promoter and a $\beta$-galactosidase reporter gene in a pGL3-Basic vector backbone.

\subsection{Cell transfection and measurement of reporter gene activity}

The MCF-7 (human mammary adenocarcinoma) cell line was cultured in HEPES-buffered DMEM/F12 medium supplemented with $10 \%$ fetal calf serum and $2 \mu \mathrm{g} / \mathrm{ml}$ insulin. Nontransformed MCF-10A cells (human mammary epithelial) were cultured in the same medium with the addition of $20 \mathrm{ng} / \mathrm{ml}$ EGF and $50 \mathrm{nM}$ hydrocortisone. HeLa (human cervical adenocarcinoma), HEK 293 (human embryonic kidney) and BHK-21 (baby hamster kidney) cell 
lines were cultured in DMEM supplemented with $10 \%$ fetal calf serum. MCF-7 and MCF-10A cells were respectively transfected using Lipofectamine 2000 (Invitrogen) and jetPEI (Polyplustransfection, Illkirch, France). HeLa, HEK 293 and BHK-21 cells were transfected using the FuGene-6 Transfection Reagent (Roche Diagnostics, Meylan, France). Briefly, cells were seeded at appropriated density in 12-well plates and transfected with $0.8 \mu \mathrm{g}$ of luciferase construct plus $0.2 \mu \mathrm{g}$ of $\mathrm{pCMV}-\beta \mathrm{Gal}$. All cell types were harvested $30 \mathrm{~h}$ post-transfection, disrupted in passive lysis buffer (Promega) and reporter gene activities were measured using the luciferase assay reagent (Promega) and $o$-nitrophenyl $\beta$-D-galactopyranoside as substrate. Luciferase activity was normalized for variations in transfection efficiency using $\beta$-galactosidase activity. Results are expressed as fold increases with regard to the promoterless vector pGL3-Basic.

\subsection{Preparation of nuclear extracts and electrophoretic mobility shift assay (EMSA)}

MCF-7 cells were stimulated or not for 15 min with $20 \mathrm{ng} / \mathrm{ml} \mathrm{TNF} \alpha$ and were harvested in icecold PBS. Cell pellets were solubilized for $5 \mathrm{~min}$ at $4^{\circ} \mathrm{C}$ in EMSA I buffer $(50 \mathrm{mM}$ Tris- $\mathrm{HCl}, 10$ $\mathrm{mM} \mathrm{KCl}, 1 \mathrm{mM}$ EDTA, $0.2 \%$ NP-40, $10 \%$ glycerol, pH=7.9) containing $100 \mathrm{mM} \mathrm{NaF}, 2 \mathrm{mM}$ $\mathrm{Na}_{3} \mathrm{VO}_{4}$ and protease and phosphatase inhibitor cocktails (Roche Diagnostics). Lysates were then centrifuged at $6500 \mathrm{~g}$ for $3 \mathrm{~min}$ and pelleted nuclei further incubated for $20 \mathrm{~min}$ at $4^{\circ} \mathrm{C}$ in EMSA II buffer (20 mM Hepes, $400 \mathrm{mM} \mathrm{NaCl}, 10 \mathrm{mM} \mathrm{KCl}, 1 \mathrm{mM}$ EDTA, $20 \%$ glycerol, pH=7.9) containing protease and phosphatase inhibitors. Nuclear extracts were centrifuged at $14,000 \mathrm{~g}$ for $10 \mathrm{~min}$ and supernatants were adjusted to a protein concentration of $1 \mathrm{mg} / \mathrm{ml}$ before being used for EMSA. Assays were performed in a $12 \mu \mathrm{l}$ total volume of binding buffer ( $20 \mathrm{mM}$ Hepes, 70 $\mathrm{mM} \mathrm{NaCl}, 2 \mathrm{mM}$ dithiothreitol, $4 \%$ Ficoll, $0.01 \% \mathrm{NP}-40,100 \mu \mathrm{g} / \mathrm{ml}$ bovine serum albumin, $\mathrm{pH}=7.5)$ containing $1 \mu \mathrm{g}$ of poly $(\mathrm{dI}-\mathrm{dC})$ and $1 \mathrm{ng}$ of $\left[{ }^{32} \mathrm{P}\right]$-labeled double-stranded probe 
(approximately 100,000 $\mathrm{cpm} \mathrm{ng}^{-1}$ ). The binding reaction was initiated by adding $5 \mu \mathrm{g}$ of nuclear extract, containing or not a 50 fold excess of unlabeled double-stranded competitor. Mixtures were then incubated for $20 \mathrm{~min}$ at room temperature prior to analysis on a non-denaturating $5 \%$ polyacrylamide gel. The gel was then dried under vacuum and subjected to autoradiography.

\subsection{Data analysis}

Data were analyzed with GraphPad Prism software (GraphPad Software, San Diego, CA, USA) using either two-tailed paired t-test or one-way ANOVA followed by Turkey's test. 


\section{Results \\ 3.1. Identification and frequency of -4825 ins polymorphism}

In the frame of previous work aiming to investigate the functional characteristics of the promoter region of the gene encoding $\alpha_{2 \mathrm{~B}}-\mathrm{AR}$ [6], the screening of a human fetal brain genomic DNA library has allowed us to isolate a $10 \mathrm{~kb} E c o \mathrm{RI}-K p n \mathrm{I}$ fragment containing $5.5 \mathrm{~kb}$ of the 5'flanking region. Sequencing indicated that the isolated fragment corresponds to the long form of $\alpha_{2 B}-A R$, i.e. the allele without deletion at position +901 in the coding region. The complete sequence of this region (GenBank accession number $\underline{\mathbf{A F 0 0 5 9 0 0}}$ ) was compared to that of a BAC clone (RP11-139J6) obtained in the frame of the human genome program (accession number $\underline{\mathbf{A C 0 9 2 6 0 3}}$ ), which corresponds to the short form of $\alpha_{2 B}$-AR (i.e. with the 9-nucleotide deletion at position +901). Besides the already reported SNPs at position $-98(-98 \mathrm{G} / \mathrm{C})$ and +1182 (+1182 C/A), which are known to be in strict linkage with the +901 Del polymorphism [6], alignment of the two sequences showed a major divergence in a region far upstream from the start codon. As seen in Fig. 1A, this variation consists of the insertion of 12 nucleotides (GGGACGGCCCTG) at position -4825 , and was thus termed -4825 ins. The two sequences were also checked for other SNPs previously described in the promoter and coding regions [6-8]. Both sequences were identical at the 19 positions $(-2142,-1787,-1661,-1410,-1396,-1237$, $1100,-687,-587,-576,-524,-523,-514,-429,-338,+36,+120+632$ and +1135$)$ where rare SNPs have been identified. Thus, according to previously proposed nomenclature [8], our genomic sequence corresponds to haplotype 1 organization, whereas the sequence of the BAC corresponds to haplotype 3 . The respective frequencies of these two major haplotypes have been reported to be 65 and $15 \%$ in African Americans and 52 and $37 \%$ in Caucausians [8]. 
The next step of our study was therefore to determine the frequency of the -4825 ins variation in a Caucasian population. Of the 71 Finnish unrelated subjects who were genotyped, 25 were $4825 \mathrm{del} / \mathrm{del}(35 \%), 17$ were -4825 ins/ins (24\%) and 29 were of the heterozygous genotype (41 $\%$ ), indicating that this newly discovered polymorphism is common. As illustrated in Fig. 1B, the -4825 ins polymorphism was found to be in complete linkage with the +901 Del polymorphism. All carriers of the heterozygous genotype at position -4825 are heterozygous at position +901 . Furthermore, all individuals carrying the -4825 del/del genotype are +901 Ins/Ins and vice versa. Given that the $+901 \mathrm{Ins} / \mathrm{Del}$ polymorphism is strictly associated with the $-98 \mathrm{G} / \mathrm{C}$ transversion [6], the -4825 ins genotype is also associated with the presence of a $\mathrm{C}$ at position -98 and conversely.

\subsection{Consequence on transcriptional activity of $A D R A 2 B$ promoter}

To determine the functional consequence of 5'-flanking region variations, luciferase constructs were generated and assayed in transformed (MCF-7) and non-transformed (MCF-10A) human mammary epithelial cells which spontaneously express the $\alpha_{2 \mathrm{~B}}-\mathrm{AR}$ [11]. In the two cell types (Fig. 2), the construct containing the $5.5 \mathrm{~kb}$ of 5'-flanking region with the 12-nucleotide deletion at position -4825 and a $\mathrm{G}$ at -98 (pGL3/ADRA2B-5505/+3[del/G]) exhibited fairly similar activity as the previously used construct containing a shorter fragment (pGL3/ADRA2B$3160 /+3[\mathrm{G}])[6]$, indicating that the region spanning from -5505 to -3160 does not contain major repressor or enhancer element. In agreement with previous results obtained in a different cellular context [6], the shorter constructs pGL3/ADRA2B-1034/+3 containing a $\mathrm{G}$ or a $\mathrm{C}$ at position -98 exhibited similar activity. On the other hand, the comparison of the activity of pGL3/ADRA2B$5505 /+3[\mathrm{del} / \mathrm{G}]$ with that of pGL3/ADRA2B-5505/+3[ins/C] indicated that the 12-nucleotide 
insertion and the $\mathrm{G}$ to $\mathrm{C}$ transversion resulted in a large reduction of transcriptional activity (84 $\%$ and $85 \%$ decreases in MCF-7 and MCF-10A cells, respectively). The difference between the two constructs was repeatedly found with 4 independent plasmid DNA preparations so that the observed change is not attributable to differences in DNA quality. Similar differences in activity were also observed in other cell-lines (HEK 293, HeLa, BHK-21) that do not express $\alpha_{2 \mathrm{~B}}$-AR (Table 2).

In silico analysis of the consequences of the -4825 ins polymorphism on potential cis-acting elements predicted that the insertion of GGGACGGCCCTG does not disrupt consensus sequences for any known transcription factor, but creates putative binding sites for NF- $\mathrm{kB}$ (TGGGGACGGCCCTGA) and MZF-1 (TGGGGAC). Since members of the NF- $\kappa$ B family have the capacity to form homo- or hetero-dimers and can behave either as activators or repressors of transcription [12], the effect of TNF $\alpha$ treatment was tested. As expected, the treatment of HEK 293 cells for $16 \mathrm{~h}$ with human $\mathrm{TNF} \alpha(20 \mathrm{ng} / \mathrm{ml})$ caused a 30 -fold increase in the activity of the pNF- $\mathrm{KB}-$ Luc construct, but induced a similar decrease in the activity of pGL3/ADRA2B5505/+3[del/G] and pGL3/ADRA2B-5505/+3[ins/C] (-77 and -78\% respectively; data not shown), indicating that the 12-nucleotide insertion does not influence the response to this cytokine. MZF-1 is a bi-functional transcriptional regulator, acting as an activator in cells of hematopoietic origin and as a repressor in other cell types [13]. A role for MZF-1 in the repression of -4825ins/-98C allele appears unlikely because impairment of the transcriptional activity of pGL3/ADRA2B-5505/+3[ins/C] was observed in HEK 293 or MCF-7 cells, which do not express this transcription factor $[14,15]$. In further support with this view, co-transfection of these two cell-lines with a constant amount of each luciferase construct and increasing amounts of CB6-MZF-1 did not reveal any effect of this transcription factor on promoter activity (data not shown). 


\subsection{Impact on the formation of DNA-nuclear protein complexes}

As a first attempt to identify DNA-binding proteins on the short and the long alleles, EMSA were performed using relevant double stranded oligonucleotides (Table 1). As illustrated in Fig 3, the ADRA2B-del and ADRA2B-ins probes gave rise to different retardation profiles after incubation with nuclear extracts prepared from MCF7 cells. A single retarded band (termed A) was observed with the ADRA2B-del probe. The formation of complex A was prevented by the addition of an excess of the corresponding unlabeled oligonucleotide (homologous competition), but was hugely increased in the presence of the NF- $\mathrm{B}$ B oligonucleotide. On the other hand, the ADRA2B-ins probe gave rise to several retarded bands, two of which were specific as they were strongly inhibited by the addition of homologous competitor. The upper band, which exhibits the same relative mobility but much stronger signal intensity than that found with the ADRA2B-del probe, likely corresponds to the same complex as band A and was therefore termed A'. As expected, the formation of complex A' was blunted by homologous competition. However, in clear contrast with that observed for complex A, its intensity was unaffected by the addition of $\mathrm{NF}-\kappa \mathrm{B}$ competitor. Another major difference between the ins- and the del-probe is the presence of another complex exhibiting lower molecular weight (termed B) whose formation is totally

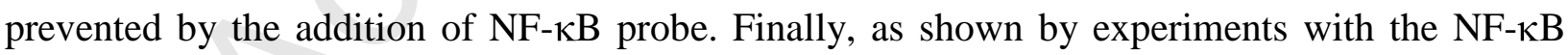
probe (right panel), none of the formed complexes corresponded to the classical p50-p65 NF- $\mathrm{BB}$ dimer, which exhibited lower mobility and was only observed when nuclear extracts prepared from TNF-treated MCF7 cells were used. 


\section{Discussion}

Experiments carried out on heterologous cell systems have demonstrated that the deletion of 9 nucleotides encoding 3 glutamic acid residues located in the third intracellular loop of the $\alpha_{2 B^{-}}$ AR attenuates receptor phosphorylation/desensitization [3] and may therefore result in enhanced receptor function in vivo. Several epidemiological studies reported a possible link between the +901 Del polymorphism and an augmented risk of cardiovascular diseases[9, 16, 17]. The existence and nature of such associations are, however, unclear, as inconsistent results have been reported and because the genetic associations have not necessarily reflected changes in receptormediated responses $[4,18]$. The +901 Del polymorphism has, however, been associated with exaggerated coronary constriction in response to adrenaline infusion [19]. In another trial, homozygous carriers of the Del allele exhibited augmented peripheral vasoconstriction within the first minutes following dexmedetomidine administration, but the enhanced response was not sustained [20]. On the other hand, measurement of dorsal hand vein diameter demonstrated no contribution of the +901 Del polymorphism to inter-individual variability in venoconstriction responses to dexmedetomidine or azepexole infusion [21, 22]. In agreement with this conclusion, a study of the hemodynamic effects of yohimbine showed that this $\alpha_{2 B}-A R$ variation is not a major determinant of variability in blood pressure responses to $\alpha_{2}$-antagonists [7]. The failure to demonstrate an impact of this polymorphism on the constrictive responses to $\alpha_{2}$-agonists may be due to the presence of all three $\alpha_{2}$-AR subtypes in the vasculature; therefore, the specific contribution of $\alpha_{2 B}-A R$ is extremely difficult to evaluate with subtype non-selective agonists. Alternatively, the lack of clear functional consequences in vivo might be due to yet unknown variations in non-coding regions of ADRA2B that would attenuate the consequences of the +901 Del polymorphism. 
The main finding of the present work is the identification of a novel common 12-nucleotide deletion/insertion polymorphism in the distal upstream region of the ADRA2B gene (-4825 del/ins) and its association with modified transcriptional activity. Based on the genotyping of a cohort of 71 unrelated Finnish individuals, the -4825 insertion variant is in complete linkage with the deletion variant in the coding region (+901 Ins/Del). As the +901 Ins/Del variation is strictly linked with the $-98 \mathrm{G} / \mathrm{C}$ polymorphism [6], the $-4825 \mathrm{del} / \mathrm{-98} \mathrm{G} /+901 \mathrm{Ins}$ and the -4825 ins / $98 \mathrm{C} /+901$ Del alleles correspond to haplotypes 1 and 3 of the ADRA2B gene [8]. Transfection of different cell types, expressing spontaneously the $\alpha_{2 \mathrm{~B}}-\mathrm{AR}$ or not, demonstrated that the promoter region containing the 12-nucleotide insertion at position -4825 and a $\mathrm{C}$ at position -98 exhibits strongly attenuated transcriptional activity. The mechanism accounting for impaired activity remains to be clarified. As already suggested by our previous study in another cellular context [6], the difference in transcriptional activity seems not to be due to the $-98 \mathrm{G} / \mathrm{C}$ substitution since luciferase constructs with a shorter promoter region and containing a $\mathrm{G}$ or $\mathrm{C}$ exhibited identical transcription activity in MCF-10A and MCF-7 cells. The 12-nucleotide insertion created a putative binding site for MZF-1; however involvement of this transcription factor can be eliminated as the difference in activity between allele is found in cells lacking MZF-1 and because co-transfection of these cells with MZF-1 did not further affect activity. Interestingly, the results of EMSA with oligonucleotide probes corresponding to the del or the ins allele showed that the region of ADRA2B where the -4825 del/ins polymorphism occurs binds nuclear proteins and that the insertion of GGGACGGCCCTG affected the pattern of bound factors in at least two respects. First, both del and ins probes gave rise to complexes exhibiting the same apparent mobility (A and A') which likely correspond to the same transcription factor(s), but clearly diverge in intensity and by the fact that their formation is differently affected in the presence of a NF- $\mathrm{KB}$ competitor. Indeed, whereas the formation of complex A is 
surprisingly enhanced in the presence of NF-kB competitor, that of complex A' is not. Given that the two alleles do not differ in their response to $\mathrm{TNF} \alpha$ treatment, this divergence may only have subtle functional consequences, if any. Moreover, neither A nor A' is expected to reflect binding of a transcription factor belonging to the NF- $\mathrm{KB}$ family, as these complexes were also formed in the absence of $\mathrm{TNF} \alpha$ treatment and were not blunted by the NF- $\mathrm{KB}$ competitor. Second, the ins probe, but not del probe, was specifically recognized by an additional factor (B) whose binding was completely blunted in the presence of the NF-KB competitor. Thus, complex B exhibited affinity for the NF- $\mathrm{kB}$ consensus sequence and likely corresponds to a transcription factor which binds to the 12 nucleotide insertion. On the basis of its small molecular weight, complex B may be a factor devoid of transactivation domain and acting as a repressor, thus accounting for the impaired transcriptional activity of the -4825 ins allele.

The potential impact of the difference in transcriptional activity observed in vitro remains to be investigated in vivo. Indeed, according to the haplotype organization, the -4825 ins and $-98 \mathrm{G} / \mathrm{C}$ polymorphisms are in linkage with the $+1182 \mathrm{C} / \mathrm{A}$ and $+1776 \mathrm{C} / \mathrm{A}$ transversions, which are located in the ORF and the 3'-UTR, and may also affect gene expression. Because there is no known human tissue expressing only the $\alpha_{2 \mathrm{~B}}-\mathrm{AR}$, and because no ligand truly selective for the $\alpha_{2 B}-A R$ subtype is available, ADRA2B mRNA quantification appears currently the only way to approach the question of functional significance.

In conclusion, the present work describes a novel deletion/insertion polymorphism in the distal promoter of the human ADRA2B gene (-4825 ins) that is in strict linkage with the +901 Del polymorphism in its coding region. Assessment of the strength of the linkage between the polymorphisms in the promoter and the coding region of ADRA2B in a non-Scandinavian population may also help to understand some of the discrepancies seen in the results of geneticepidemiological studies of cardiovascular morbidity $[4,5]$. The -4825 ins allele is associated 
1

with markedly reduced transcriptional activity. The functional impact of this novel promoter polymorphism on $\alpha_{2 \mathrm{~B}}-\mathrm{AR}$ expression will merit to be examined in vivo, as a decrease in receptor expression could in part compensate for the previously reported refractoriness of the mutated $\alpha_{2 \mathrm{~B}}-\mathrm{AR}$ to desensitization and would thus lessen its adverse consequences. 


\section{Acknowledgements}

This work was supported by grants from the Ministère de l'Éducation Nationale de la Recherche et de la Technologie (P-A Crassous), the Finnish Heart Foundation, the Jusélius Foundation and Turku University Hospital (M Scheinin). 


\section{References}

[1] K.M. Small and S.B. Liggett, Identification and functional characterization of $\alpha_{2^{-}}$ adrenoceptor polymorphisms, Trends Pharmacol Sci 22 (2001), pp. 471-477.

[2] P. Heinonen, M. Koulu, U. Pesonen, M.K. Karvonen, A. Rissanen, M. Laakso et al., Identification of a three-amino acid deletion in the $\alpha_{2 \mathrm{~B}}$-adrenergic receptor that is associated with reduced basal metabolic rate in obese subjects, J Clin Endocrinol Metab 84 (1999), pp. 2429-2433.

[3] K.M. Small, K.M. Brown, S.L. Forbes and S.B. Liggett, Polymorphic deletion of three intracellular acidic residues of the $\alpha_{2 \mathrm{~B}}$-adrenergic receptor decreases $\mathrm{G}$ protein-coupled receptor kinase-mediated phosphorylation and desensitization, J Biol Chem 276 (2001), pp. 4917-4922.

[4] D. Rosskopf and M.C. Michel, Pharmacogenomics of G protein-coupled receptor ligands in cardiovascular medicine, Pharmacol Rev 60 (2008), pp. 513-535.

[5] S. Schaak, J. Mialet-Perez, C. Flordellis and H. Paris, Genetic variation of human adrenergic receptors: from molecular and functional properties to clinical and pharmacogenetic implications, Curr Top Med Chem 7 (2007), pp. 217-231.

[6] C. Cayla, P. Heinonen, L. Viikari, S. Schaak, A. Snapir, A. Bouloumie et al., Cloning, characterisation and identification of several polymorphisms in the promoter region of the human $\alpha_{2 B}$-adrenergic receptor gene, Biochem Pharmacol 67 (2004), pp. 469-478.

[7] J.P. Etzel, B.K. Rana, G. Wen, R.J. Parmer, N.J. Schork, D.T. O'Connor et al., Genetic variation at the human $\alpha_{2 \mathrm{~B}}$-adrenergic receptor locus: role in blood pressure variation and yohimbine response, Hypertension 45 (2005), pp. 1207-1213. 
[8] M. Muszkat, D. Kurnik, J. Solus, G.G. Sofowora, H.G. Xie, L. Jiang et al., Variation in the $\alpha_{2 \mathrm{~B}}$-adrenergic receptor gene (ADRA2B) and its relationship to vascular response in vivo, Pharmacogenet Genomics 15 (2005), pp. 407-414.

[9] A. Snapir, P. Heinonen, T.P. Tuomainen, P. Alhopuro, M.K. Karvonen, T.A. Lakka et $a l .$, An insertion/deletion polymorphism in the $\alpha_{2 \mathrm{~B}}$-adrenergic receptor gene is a novel genetic risk factor for acute coronary events, J Am Coll Cardiol 37 (2001), pp. 15161522.

[10] S. Schaak, J.C. Devedjian, C. Cayla, Y. Sender and H. Paris, Molecular cloning, sequencing and functional study of the promoter region of the human $\alpha 2 \mathrm{C} 4$-adrenergic receptor gene, Biochem J 328 (1997), pp. 431-438.

[11] S.M. Vazquez, A.G. Mladovan, C. Perez, A. Bruzzone, A. Baldi and I.A. Luthy, Human breast cell lines exhibit functional $\alpha_{2}$-adrenoceptors, Cancer Chemother Pharmacol 58 (2006), pp. 50-61.

[12] M.S. Hayden and S. Ghosh, Signaling to NF-кB, Genes Dev 18 (2004), pp. 2195-2224.

[13] R. Hromas, B. Davis, F.J. Rauscher, 3rd, M. Klemsz, D. Tenen, S. Hoffman et al., Hematopoietic transcriptional regulation by the myeloid zinc finger gene, MZF-1, Curr Top Microbiol Immunol 211 (1996), pp. 159-164.

[14] J.F. Morris, F.J. Rauscher, 3rd, B. Davis, M. Klemsz, D. Xu, D. Tenen et al., The myeloid zinc finger gene, MZF-1, regulates the CD34 promoter in vitro, Blood 86 (1995), pp. 3640-3647.

[15] S. Dong, Z. Zhang and H. Takahara, Estrogen-enhanced peptidylarginine deiminase type IV gene (PADI4) expression in MCF-7 cells is mediated by estrogen receptor- $\alpha$ promoted transfactors activator protein-1, nuclear factor-Y, and Sp1, Mol Endocrinol 21 (2007), pp. 1617-1629. 
[16] A. Snapir, J. Mikkelsson, M. Perola, A. Penttila, M. Scheinin and P.J. Karhunen, Variation in the $\alpha_{2 \mathrm{~B}}$-adrenoceptor gene as a risk factor for prehospital fatal myocardial infarction and sudden cardiac death, J Am Coll Cardiol 41 (2003), pp. 190-194.

[17] F. Von Wowern, K. Bengtsson, U. Lindblad, L. Rastam and O. Melander, Functional variant in the $\alpha_{2 \mathrm{~B}}$-adrenoceptor gene, a positional candidate on chromosome 2 , associates with hypertension, Hypertension 43 (2004), pp. 592-597.

[18] S.L. Kirstein and P.A. Insel, Autonomic nervous system pharmacogenomics: a progress report, Pharmacol Rev 56 (2004), pp. 31-52.

[19] A. Snapir, J. Koskenvuo, J. Toikka, M. Orho-Melander, S. Hinkka, M. Saraste et al.,

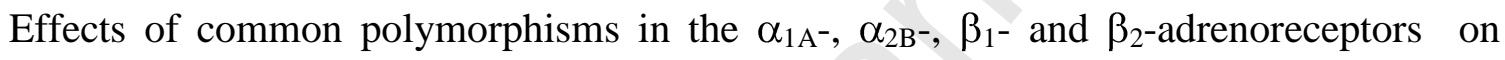
haemodynamic responses to adrenaline, Clin Sci (Lond) 104 (2003), pp. 509-520.

[20] P. Talke, C. Stapelfeldt, E. Lobo, R. Brown, M. Scheinin and A. Snapir, Alpha ${ }_{2 B^{-}}$ adrenoceptor polymorphism and peripheral vasoconstriction, Pharmacogenet Genomics 15 (2005), pp. 357-363.

[21] D. King, J.P. Etzel, S. Chopra, J. Smith, P.E. Cadman, F. Rao et al., Human response to $\alpha_{2}$-adrenergic agonist stimulation studied in an isolated vascular bed in vivo: Biphasic influence of dose, age, gender, and receptor genotype, Clin Pharmacol Ther 77 (2005), pp. 388-403.

[22] M. Muszkat, G.G. Sofowora, H.G. Xie, A.J. Wood and C.M. Stein, Alpha2B adrenergic receptor 301-303 deletion polymorphism and vascular $\alpha_{2}$-adrenergic receptor response, Pharmacogenet Genomics 15 (2005), pp. 23-28. 


\section{Legends for figures}

\section{Fig. 1}

Characterization of the $-4825 \mathrm{del} /$ ins polymorphism and association with $+901 \mathrm{Ins} / \mathrm{Del}$.

(A) Electrophoregrams of the -4825 del (upper panel) and -4825 ins (lower panel) alleles of the ADRA2B gene.

(B) PCR/RFLP-based genotyping for the -4825 del/ins (upper panel) and +901 Ins/Del (lower panel) polymorphisms.

\section{Fig. 2}

Transcriptional activity of luciferase constructs.

MCF-7 (left panel) and MCF-10A (right panel) cells were transfected with the indicated constructs as described in the "Materials and methods" section. Data are expressed as fold increases relative to the activity of the promoterless construct pGL3-Basic and presented as mean \pm S.E.M. from 4 to 7 independent experiments performed in duplicate. Data were analyzed using ANOVA followed by Tukey's post test. Statistically significant differences between pGL3/ADRA2B-5505/+3[del/G] and pGL3/ADRA2B-5505/+3[ins/C] are indicated by asterisks (* $P<0.01 ; * * P<0.001)$.

\section{Fig. 3}

Nuclear factor binding to the polymorphic region of the ADRA2B gene promoter.

EMSA were performed using MCF-7 nuclear extracts, with probes corresponding to both -4825 variants of the ADRA2B gene (ADRA2B-del and ADRA2B-ins; left panels) or to NF- $\mathrm{B}$ consensus sequence (right panel), as described in the "Materials and methods" section. Sequences of probes and competitors used are indicated in Table 1. 
Table 1: Sequence of oligonucleotides used for EMSA

Probe

ADRA2B-del (sense)

ADRA2B-del (antisense)

ADRA2B-ins (sense)

ADRA2B-ins (antisense)

NF-kB (sense)

NF-kB (antisense)
Sequence

${ }_{5}$, GTTTATTGTGAACCTTGCA 3 ,

${ }_{5}$, GTGCAAGGTTCACAATAAA 3 ,

5,GTTTATTGTGGGGACGGCCCTGAACCTTGCA 3 ,

5,GTGCAAGGTTCAGGGCCGTCCCCACAATAAA ${ }_{3}$,

5, GATCTGGGGATTCCCCAT $_{3}$,

${ }_{5}$, $\underline{\text { GATCATGGGGAATCCCCA }} 3$ 
Table 2: Activity of ADRA2B promoter constructs in transfected cell lines

Luciferase construct

pGL3/ADRA2B-5505/+3 [del/G]

pGL3/ADRA2B-5505/+3 [ins/C]

$$
\text { HEK } 293
$$

$10.2 \pm 1.5$

$3.3 \pm 0.4 * *$
HeLa

$4.9 \pm 0.7$

$2.3 \pm 0.4 *$
BHK-21

$5.5 \pm 0.4$

$1.9 \pm 0.2 * *$

HEK 293, HeLa and BHK-21 cells were transfected with the indicated constructs as described in the Methods section. Data are expressed as fold increases of luciferase activity relative to the promoterless construct pGL3-Basic. Results are means \pm S.E.M. from 5 to 8 independent experiments performed in duplicate. Data were analyzed using two-tailed paired t-test. Statistically significant differences with the activity of the pGL3/ADRA2B-5505/+3[del/G] construct are indicated by asterisks $(* P<0.01 ; * * P<0.001)$. 
A
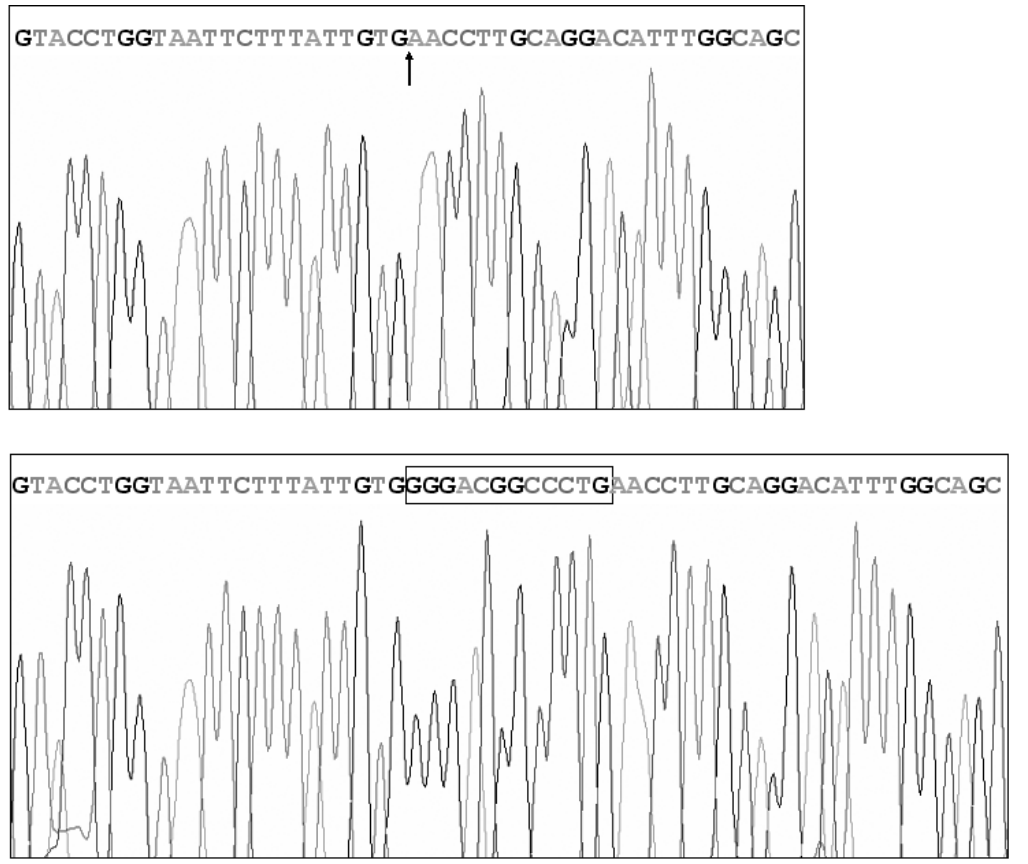

B

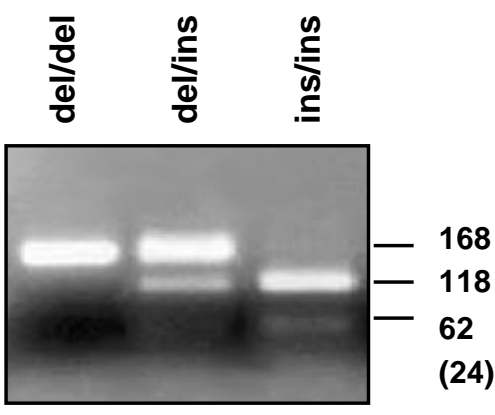

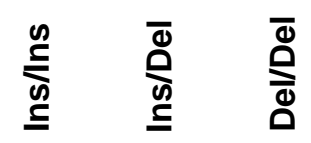

$+901$

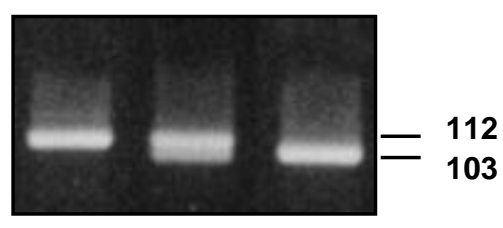

$\begin{array}{llll}\text { Subject \# } & 1 & 2 & 3\end{array}$ 
A
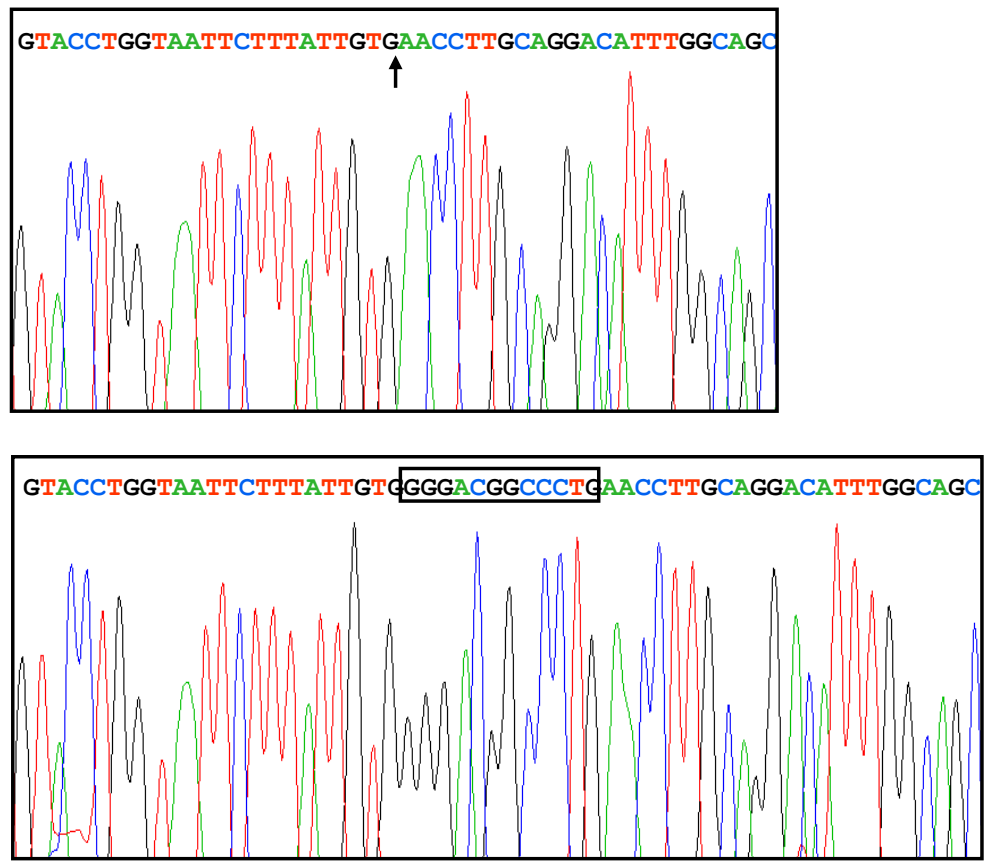

B

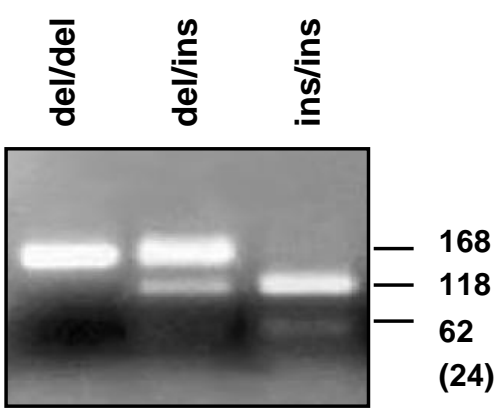

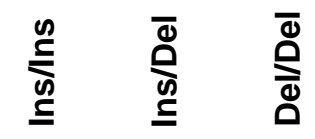

$+901$

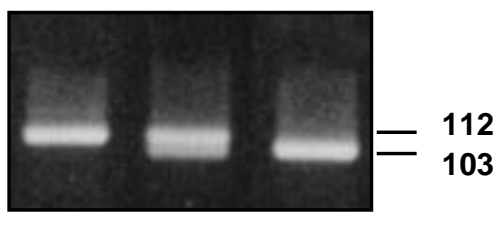

$\begin{array}{llll}\text { Subject \# } & 1 & 2 & 3\end{array}$ 

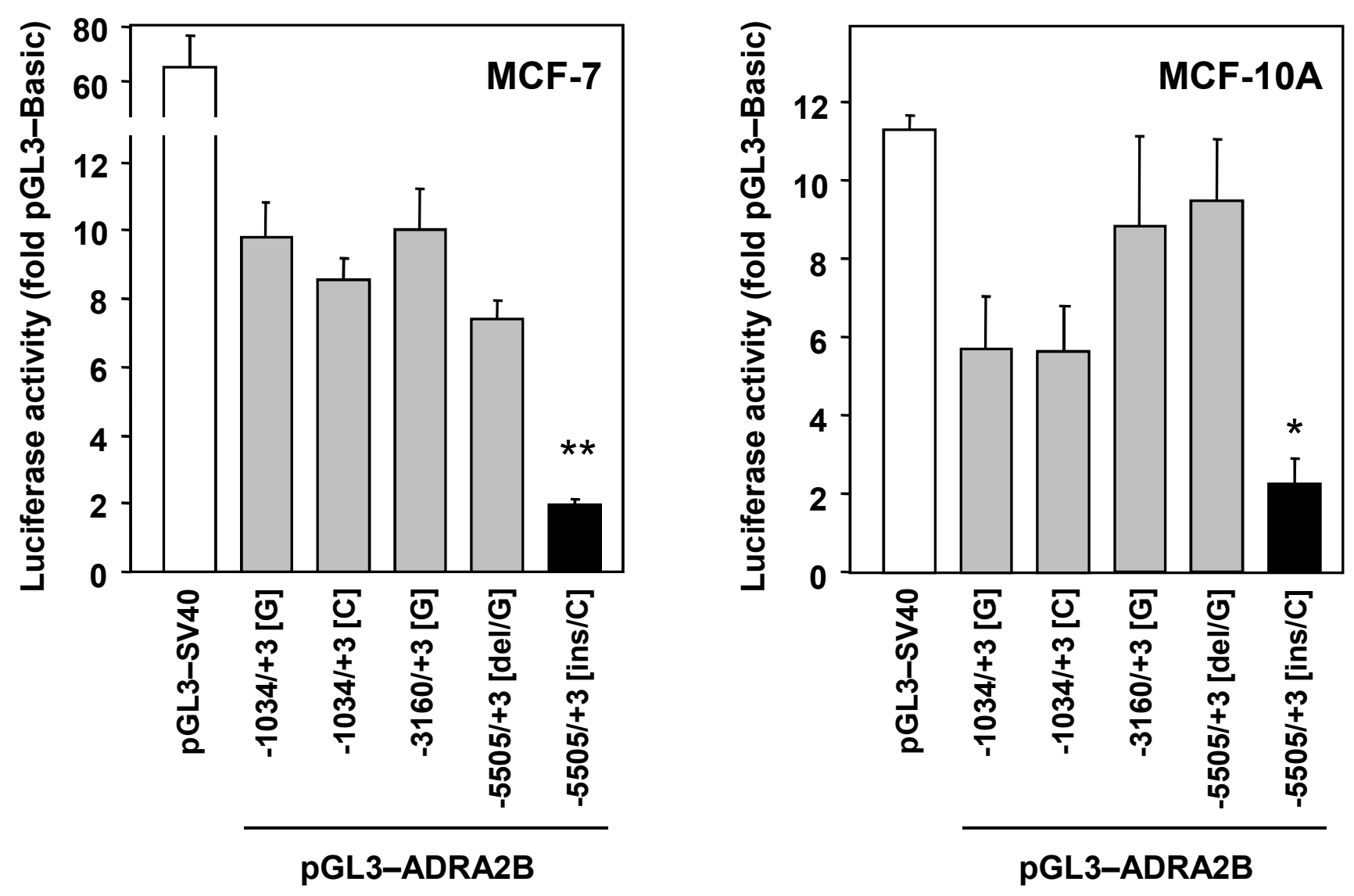


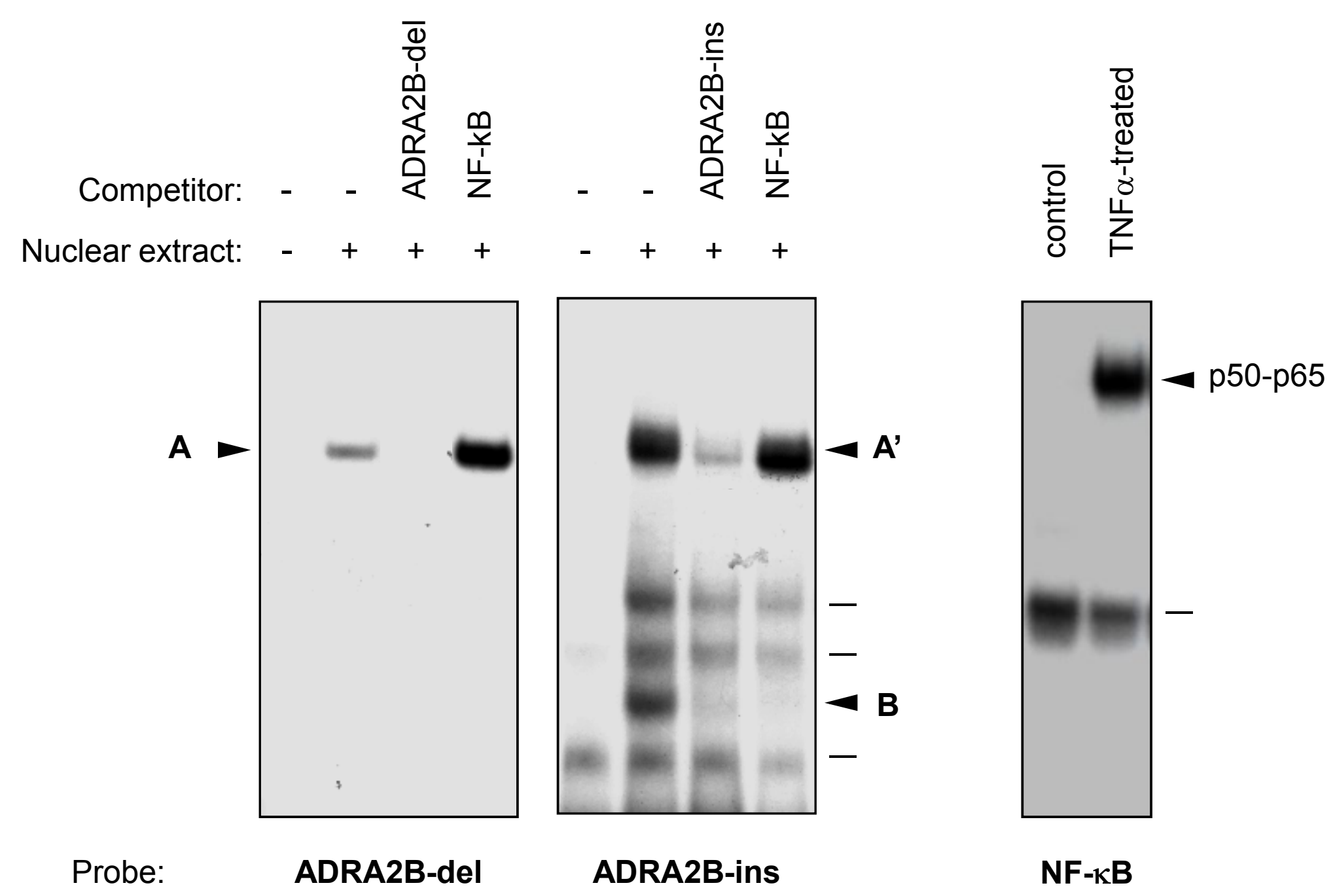



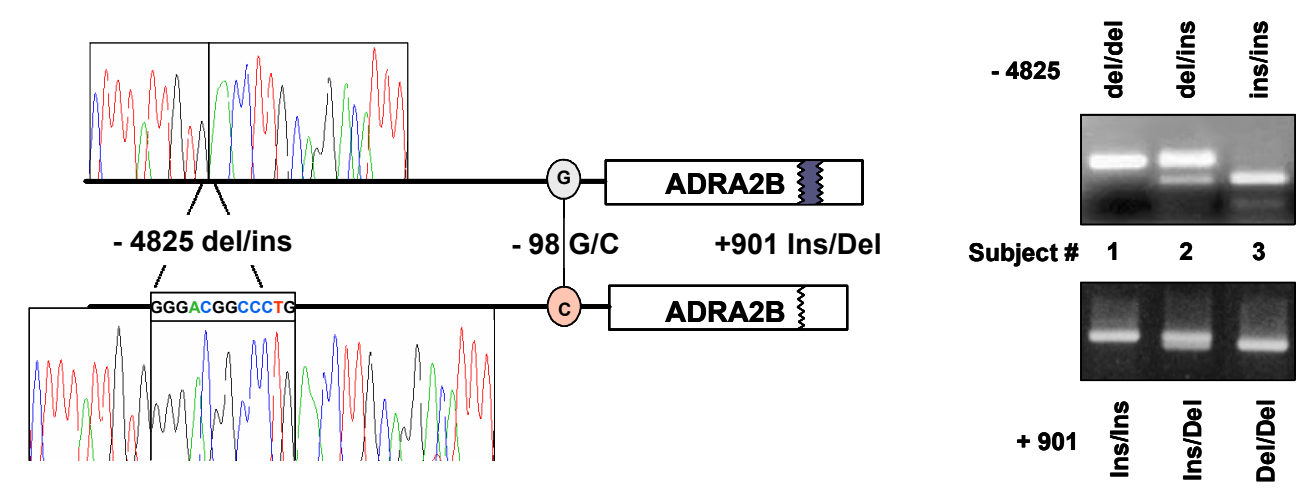